\title{
iMACHININg CUTTINg ForCe Measurement
}

\author{
Jan Hnatik, Jan Kutlwaser, Josef Sklenicka \\ Regional Technological Institute, Faculty of Mechanical Engineering, University of West Bohemia, Pilsen, Czech \\ Republic
}

\begin{abstract}
The article focuses on the issue of cutting force measurement during machining. The beginning of the article describes the motivation of cooperation between SolidCAM and University of West Bohemia. The article then contains results of tests, which are proposed to evaluate iMachining developer's assumption that the iMachining should be able to secure constant tool load. The difference between classical machining strategy and iMachining is described on the machining of open and closed pocket. The results of cutting force measurement are presented and concluded in the end of the article.
\end{abstract}

Keywords: Constant tool load; cutting force; iMachining; pocket milling; HPC
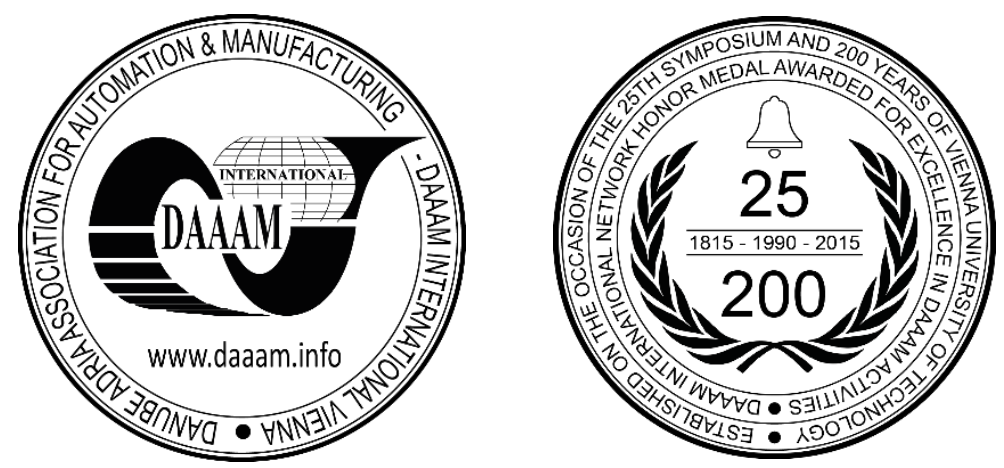

This Publication has to be referred as: Hnatik, J[an]; Kutlwaser, J[an] \& Sklenicka, J[osef] (2016). iMachining Cutting Force Measurement, Proceedings of the 26th DAAAM International Symposium, pp.0955-0959, B. Katalinic (Ed.), Published by DAAAM International, ISBN 978-3-902734-07-5, ISSN 1726-9679, Vienna, Austria DOI: $10.2507 / 26$ th.daaam.proceedings. 134 


\section{Introduction}

The world of machining changed when new strategies such as iMachining were introduced. iMachining offers higher productivity of cutting due to higher cutting speeds, optimized feed rates and especially the constant cutting force. That is the statement of the developers. But is it really true?

To prove this statement SolidCAM Ltd. has contacted the University of West Bohemia in Pilsen where the cutting force is measured by the rotational dynamometer Kistler 9123C. The basic task was to realize a test of basic strategies of milling an open and close pocket and to compare the cutting force with peripheral cutting. Anyway the problem of cutting forces during peripheral milling is important for many CAM producers. The knowledge of the cutting force and its behaviour can improve the milling strategies.

\section{Rotational dynamometer}
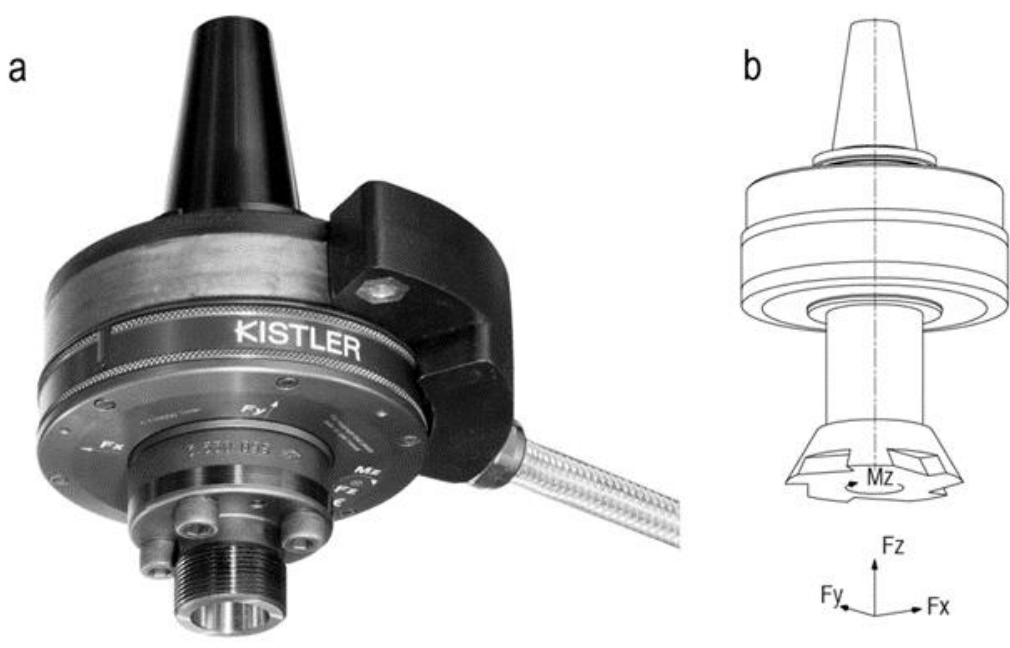

Fig. 1. Rotating dynamometer KISTLER (a) Cutting force component (b) [6]

The dynamometer (fig. 1a) can measure the components of the force in three basic directions - X, Y, Z and the torque M (Fig. 1b). In the graphs below, $\mathrm{X}$ is the direction of tangential force. So the tangential force is marked as Fx. This component of the cutting force is important for the calculation of the torque and thus the cutting power of the machine. This is the reason why the Fx is displayed in the figures below.

While the dynamometer rotates together with the tool the cutting force changes from positive to negative values. That's the reason why the forces in the graphs are symmetrical over the horizontal axis. The important information is the envelope amplitude of the force.

When the cutting force is measured by dynamometer it is possible to see directly the load on the cutting tool. The real cutting forces are measured by the dynamometer, which is more realistic than cutting force calculation based on prediction models $[2,5]$, which are developed for many years [3]. The models of cutting force usually strongly simplify the calculation (for example effective number of teeth in cut, helix angle of the cutting edge, friction, effect of cutting speed or radius of the cutting edge [9]) and very often the material properties like specific cutting force need to be measured experimentally. Latest researches also offer the possibility to use finite element method to calculate the cutting force [10].

Anyway the cutting force models are very important for cutting force prediction in CAM systems or cutting conditions calculators [4].

\section{Open pocket}

The first test was done on a simple open pocket. In a standard machining operation the tool path would be generated around the pocket contour [1] (like a spiral - see figure 2). This would lead to full engagement of the tool. Usually, the cutting tool can cut a full slot only in a relatively shallow axial depth. This is the reason why the standard pocketing is not comparable to iMachining.

It is also possible to machine the open pocket by the tool paths parallel to open side, either one way (see figure 3a) or zig-zag. The one way tool path is more similar to iMachining, because in both cases the tool is not fully engaged and the side step seems to be constant. Anyway, in case of classical open pocket with one way tool paths, the engagement angle of the tool increases at the beginning and at the end of each cut. And this is the reason why the cutting force is higher in case of classical pocketing and the feed rate must be reduced. 
Unlike other implementations of the high speed machining paradigm, which strive to generate tool paths that control the Tool Engagement Angle (TEA) to be of a constant value [7], selected for its suitability for the material being machined and the tool being used, or those that keep the radial depth of cut constant, iMachining generates the tool paths so that the cutting force on the tool is kept constant (tool paths are shown in the figure $3 \mathrm{~b}$ ). To achieve this, iMachining requires the selection of a permitted TEA range, within which it can manoeuvre the tool path such that the force is kept constant. In addition, when the tool can't reach even the minimum permitted engagement angle (usually in the approach and retract motions), the feed is increased to level up the tool load. The overall load of the tool is then smaller and more uniform in comparison with the standard technology, enabling the increase of the overall cutting force and thus to reach higher speeds and productivity.

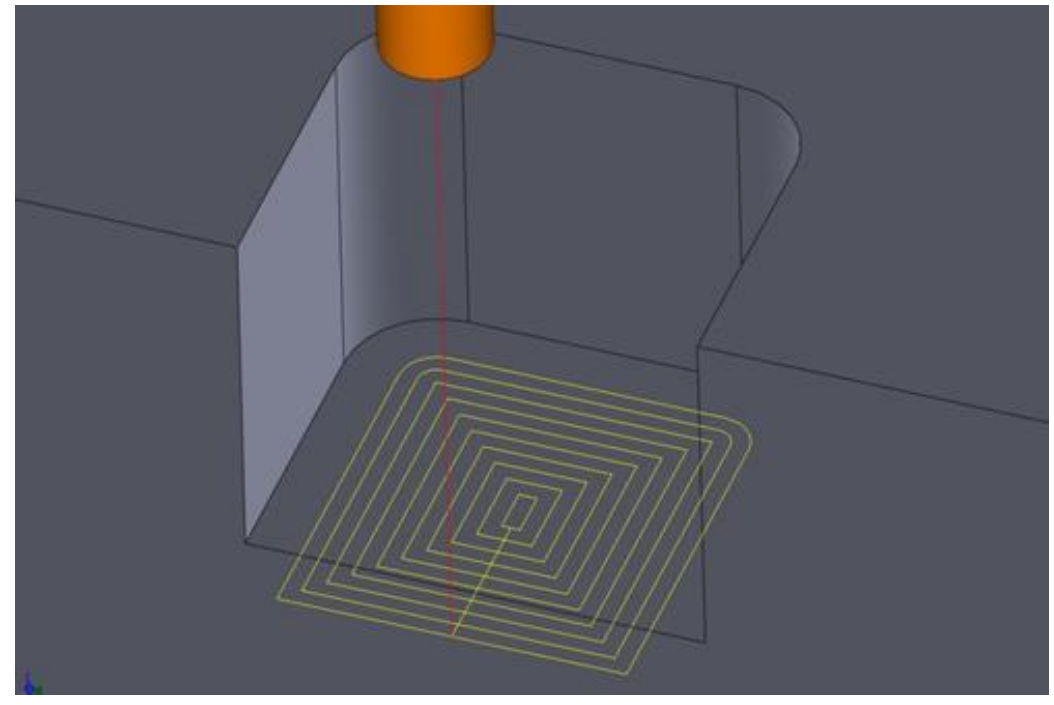

Fig. 2. classical open pocket
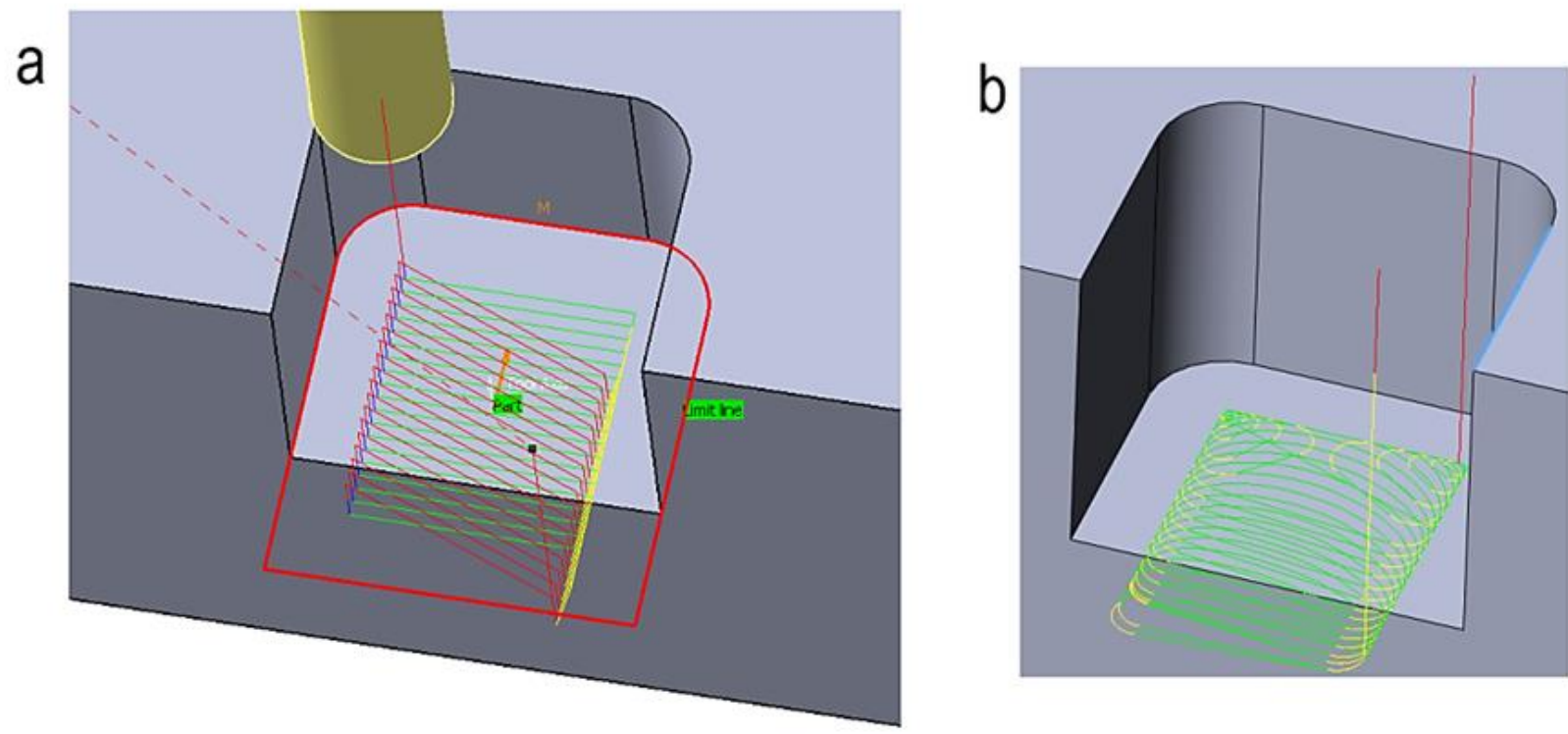

Fig. 3 (a) Classical pocket with iMachining like tool path (b) iMachining tool path in a open pocket

This all can be proved by the measured cutting forces. The side step and feed are quite similar in both cases. Thus the cutting force is also similar, $600 \mathrm{~N}$ in case of iMachining and $500 \mathrm{~N}$ in case of classical open pocket with iMachining like tool paths (see figure 4). The difference is especially at the beginning and the end of each pass. Even though the feed rate is increased in iMachining, the shape of the tool paths ensures the constant tool load. In case of classical tool path the tool load doubles up to $1200 \mathrm{~N}$ (see figure 5). This is caused by increased engagement angle and it is very dangerous for the tool. The tool wear accelerates, leading to premature tool failure and breakage. 
a

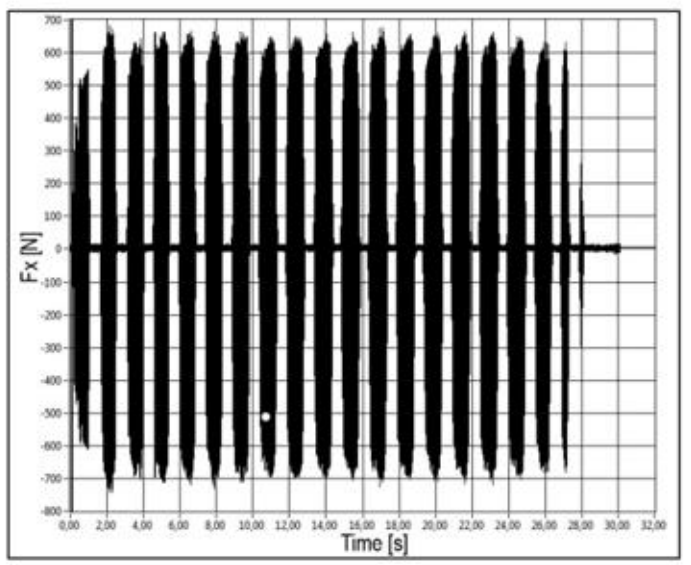

b

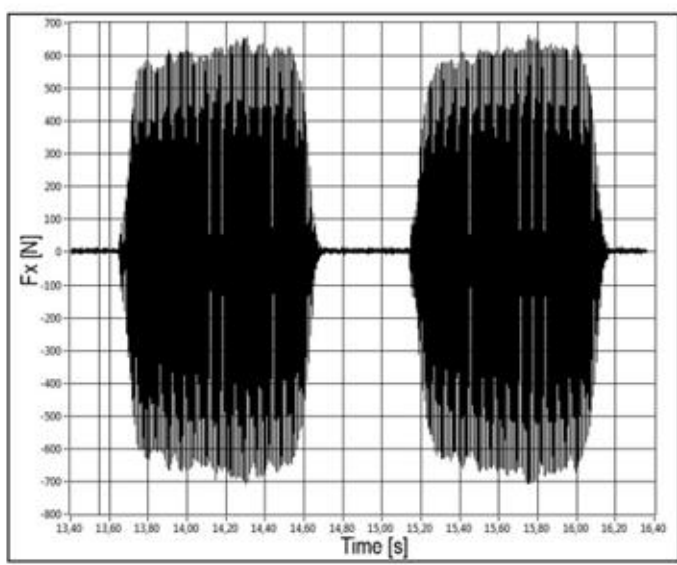

Fig. 4 (a) Constant load of the tool in iMachining open pocket and its detail (b) [8]
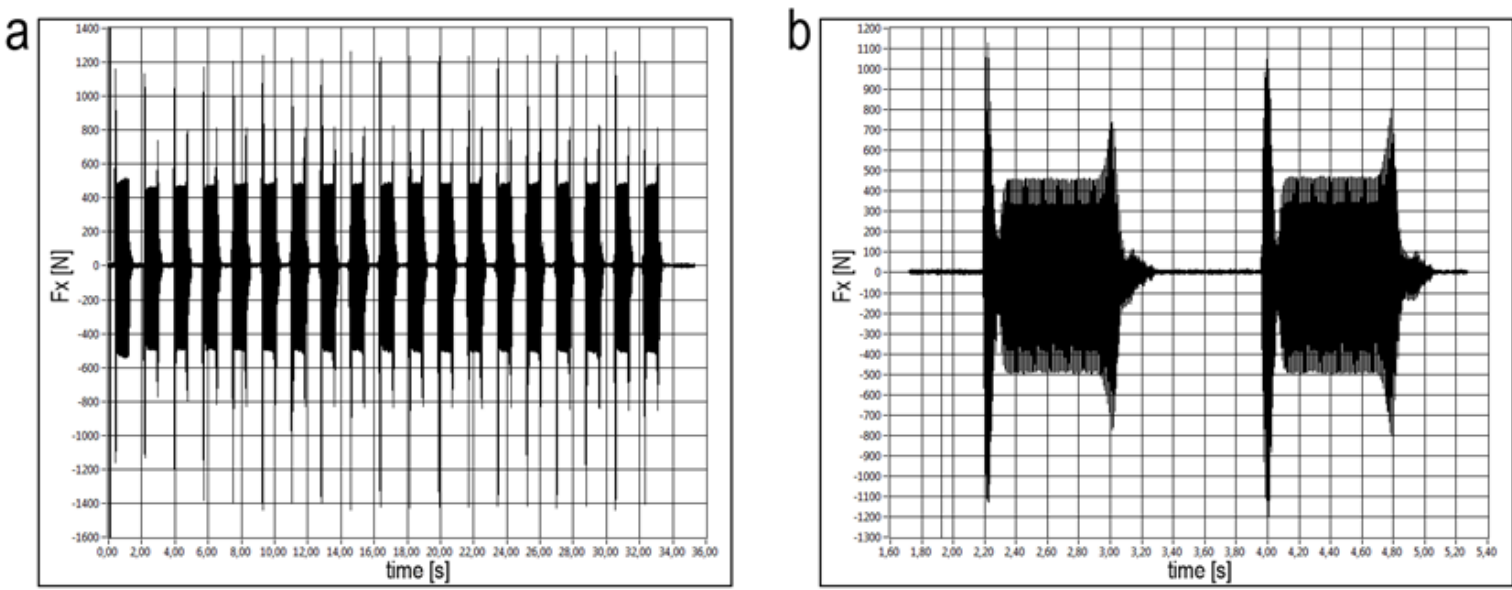

Fig. 5 (a) Tool load in the classical tool paths and its detail (b)

\section{Closed pocket}

In case of a closed pocket the difference between the classical technology and iMachining is even more obvious. In classical technology it is nearly impossible to avoid full engagement of the tool, especially in complicated shape of the pocket or in case of a pocket with islands. This is the reason why the classical strategy usually doesn't reach such a high value of axial cutting depth (Ap). The cutting process is so different that the comparison of the cutting forces is not meaningful. Anyway the behavior of the cutting force is still very interesting in case of iMachining. Because the tool paths of iMachining avoids full engagement of the tool and the engagement angle is kept within the permitted limits, independently of the shape of the pocket (open or closed), the cutting force is kept constant. The graph below shows the cutting force in the closed pocket. The value of the tangential force (its behaviour is in figure 6) reaches $600 \mathrm{~N}$ (the same value as in case of open pocket).

In the next graph the cutting force gradually decreases in the end. This smaller cutting force describes the behaviour in the corner. The feed at the contact point is smaller than the programmed feed by a factor equal to the ratio between a) the sum of the tool radius and corner radius and b) the corner radius. In addition to this reduction in feed, the same factor reduces the engagement angle below the minimum permitted limit, with the danger of chip thinning. In such cases, iMachining attempts to bring up the chip thickness by increasing the feed by an equal factor. This may not always be possible due to feed and acceleration limitations of the machine. In such cases the cutting force cannot be kept constant. One of the reasons of this effect is the maximum feed of the cutting machine. The machine is unable to accelerate to such a high feed on a small trajectory (acceleration of the DMU 65 monoBLOCK® is limited to $0.6 \mathrm{~m} / \mathrm{s} 2$ ) so in fact the programmed feed rate at the contact point is not reached. The smaller the trajectory, the smaller is the real feed reached by the machine. So, the cutting force decreases. 


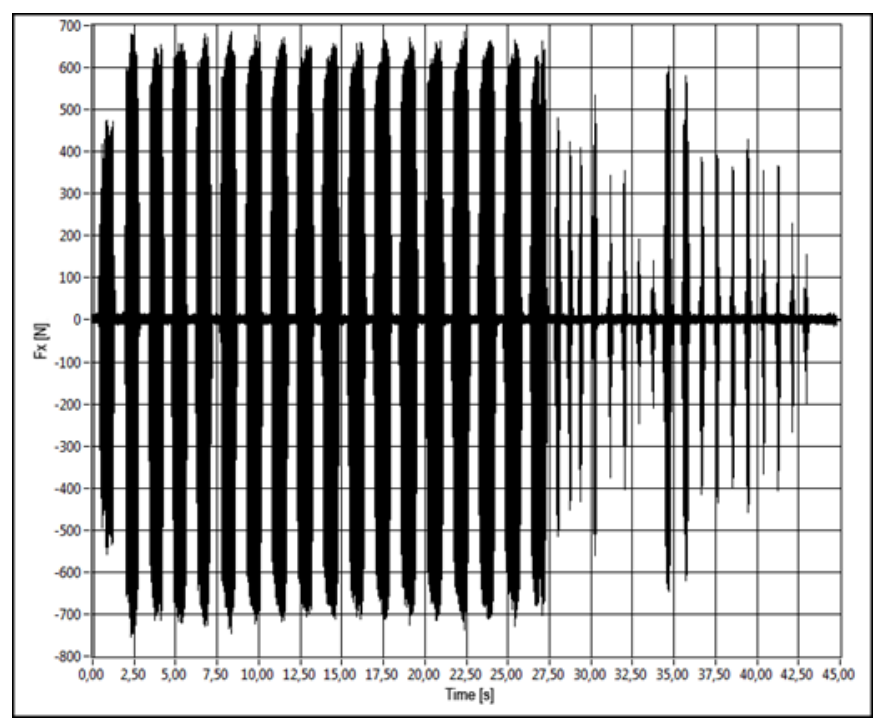

Fig. 6 Cutting force in a closed pocket

\section{Conclusion}

The main task of the test was to compare the classical machining strategy with peripheral milling which is used in iMachining. The cutting force was measured under different conditions. The measurement of the cutting force proved that iMachining is able to maintain a constant tool load during the whole operation. At the same moment the cutting force varies in case of classical milling strategy which causes higher tool load and lower tool life. The peaks of the cutting force can also cause damage of the cutting tool.

This is very important information not only for SolidCAM Ltd. but also for all the NC programmers, who can rely on iMachining and who can use higher cutting condition.

\section{Acknowledgements}

The present contribution has been prepared under project LO1502 'Development of the Regional Technological Institute' under the auspices of the National Sustainability Programme I of the Ministry of Education of the Czech Republic aimed to support research, experimental development and innovation.

\section{References}

[1] H. Perez, E. Diez, J. Perez, A. Vizan, Analysis of Machining Strategies for Peripheral Milling, Procedia engineering, Vol. 63, 2013, pp. 573-581

[2] Dang, J.-W.; Zhang, W.-H.; Yang, Y.; Wan, M.. Cutting force modeling for flat end milling including bottom edge cutting effect. International Journal of Machine Tools and Manufacture, vol. 50, pp. 986-997, 2010.

[3] G. Yücesan, Y. Altintaş, Improved modelling of cutting force coefficients in peripheral milling, International Journal of Machine Tools and Manufacture, vol. 34, Issue 4, 1994, pp 473-487

[4] Cutting conditions calculator KENNAMETAL, available on-line at

http://www.kennametal.com/en/resources/engineering-calculators/turning-calculators/cutting-forces.html, cited 14.7.2015

[5] H. Perez, E. Diez, J. Perez, A. Vizan, An enhanced method for cutting force estimation in peripheral milling, Internation Journal of Advanced Manufacturing Technology, 69, 1731-1741, 2013, Springer-Verlag, London

[6] Kistler 9123C operating manual, KISTLER Instrumente AG, 2005, Winthertur

[7] Soichi Ibaraki, , Iwao Yamaji, Atsushi Matsubara, On the removal of critical cutting regions by trochoidal grooving, Precision Engineering, Vol. 34, Issue 3, 2010, p. 467-473

[8] J. Hnátík, J. Kutlwašrr, J. Sklenička, Měření řezných sil při obrábění metodou iMachining (iMachining cutting force measurement), Strojírenská technologie (Manufacturing Technology), 2014, pp, 78-82, ISSN: 1211-4162

[9] J. Fulemová, Z. Janda, Influence of the Cutting Edge Radius and the Cutting Edge Preparation on Tool Life and Cutting Forces at Inserts with Wiper Geometry, Procedia Engineering, Volume 69, 2014, Pages 565-573, 24th DAAAM International Symposium on Intelligent Manufacturing and Automation, 2013

[10] Diana-Andreea Coroni, Sorin-Mihai Croitoru, Prediction of Cutting Forces at 2D Titanium Machining, Procedia Engineering, Volume 69, 2014, Pages 81-89, 24th DAAAM International Symposium on Intelligent Manufacturing and Automation, 2013 